\title{
Primary malignant melanoma of the lacrimal sac
}

\author{
Yang-Jun Li, ${ }^{1}$ Shao-Jun Zhu, ${ }^{2}$ Hong Yan, ${ }^{1}$ Jing Han, ${ }^{1}$ Dan Wang, ${ }^{1}$ Shuang $\mathrm{Xu}{ }^{1}$ \\ ${ }^{1}$ Department of Ophthalmology, Tangdu Hospital, The Fourth Military Medical University of PLA, Xian, People's Republic of China \\ ${ }^{2}$ Department of Pathology, Tangdu Hospital, The Fourth Military Medical University of PLA, Xian, People's Republic of China
}

Correspondence to Professor Yang-Jun Li, eyeliyjun@126.com

Y-JL and S-JZ contributed equally to this paper.

\begin{abstract}
Summary
Primary malignant melanoma of the lacrimal sac is extremely rare. It is usually diagnosed at an advanced stage after excision or biopsy of a tumour. We treated a 59-year-old man with tearing and bloody discharge from the right eye. Clinical examination revealed a firm, localised mass at the inner canthus consistent with a lacrimal sac swelling. Sac washout demonstrated obstruction to entry into the lacrimal sac with a reflux of blood-stained fluid. The pathological findings and the immunohistochemical studies showed a malignant melanoma of the lacrimal sac. We performed radical surgery and radiation therapy. Follow-up 4 months after surgery revealed no evidence of recurrence. Because this tumour often presents with symptoms similar to dacryocystitis and may masquerade as a chronic dacryocystitis, ophthalmologists should be aware of this disease entity when encountered with patients with epiphora and mass in the medial canthal area.
\end{abstract}

\section{BACKGROUND}

Tumours of the lacrimal sac are rare, and primary malignant melanoma in this region is extremely rare. Only 24 cases of primary malignant melanoma of the lacrimal sac have been reported worldwide. ${ }^{1-3}$ It is usually diagnosed late as it may mimic chronic dacryocystitis. A case of malignant melanoma of the lacrimal sac is presented and the world literature is reviewed.

\section{CASE PRESENTATION}

A 59-year-old man complained of a 6-month history of tearing and 2-month history of a single episode of rightsided epistaxis. Clinical examination revealed a firm, localised, non-tender mass at the inner canthus consistent with a lacrimal sac swelling (figure 1). Sac washout demonstrated obstruction to entry into the lacrimal sac with reflux of blood-stained fluid. Examination of the nose showed inferior turbinate swell and occlusive inferior meatus. The patient had no previous history of regional surgery or trauma. There was no history of a cutaneous primary melanoma.

\section{INVESTIGATIONS}

CT scanning of the paranasal sinus showed a soft tissue mass in the right lacrimal sac with widening and erosion of the nasolacrimal canal and inferior turbinate, attached to the medial orbital wall (figure 2A,B). However, neither orbital cavity involvement nor bony destruction was detected. In addition, infiltration of the surrounding soft tissue was not detected.

MRI showed proton density image of the right paranasal sinus. Corresponding axial MRI showed T1-weighted lowerintensity (figure 3A), T2-weighted highintensity (figure $3 \mathrm{~B}$ ) and coronal MRI gadolinium-enhanced T1-weighted (figure 3C) highintensity. A complete metastatic workup including CT scanning of the head and neck, chest, abdomen and pelvis failed to demonstrate lymphadenopathy or other evidence of metastasis. A general physical examination and routine laboratory tests were all within normal limits.
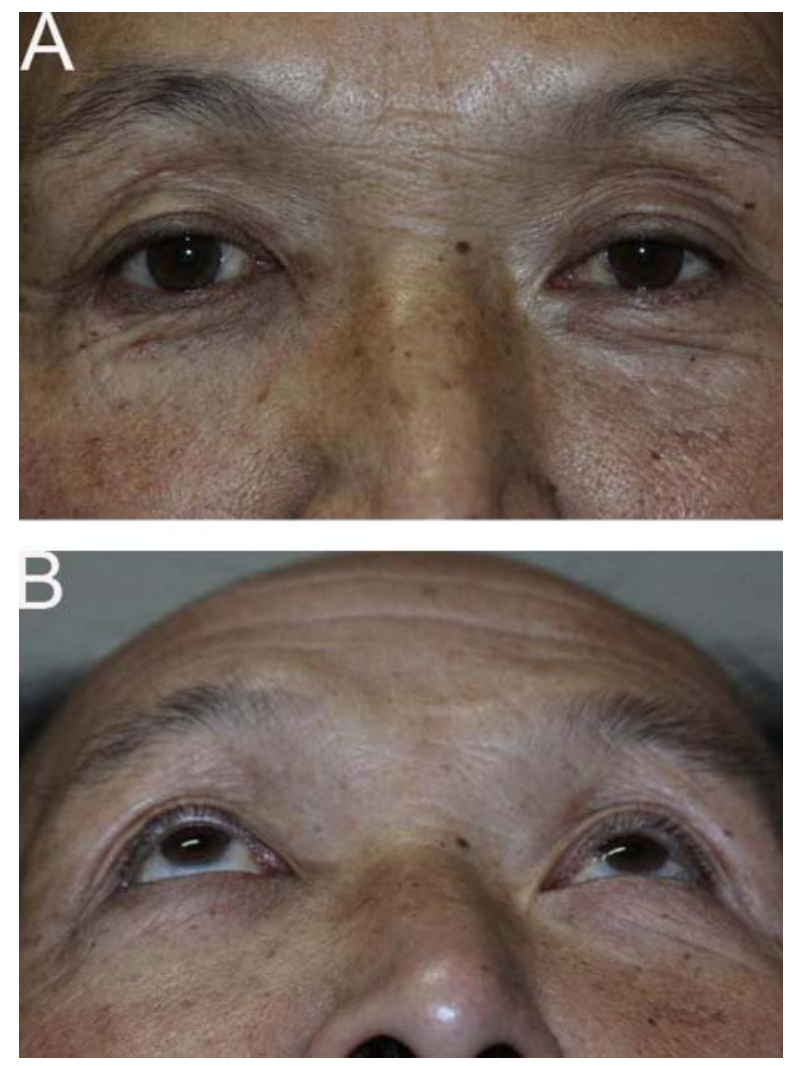

Figure 1 Clinical examination revealed a firm, localised, non-tender mass at the inner canthus consistent with a lacrimal sac swelling. 


\section{BMJ Case Reports}
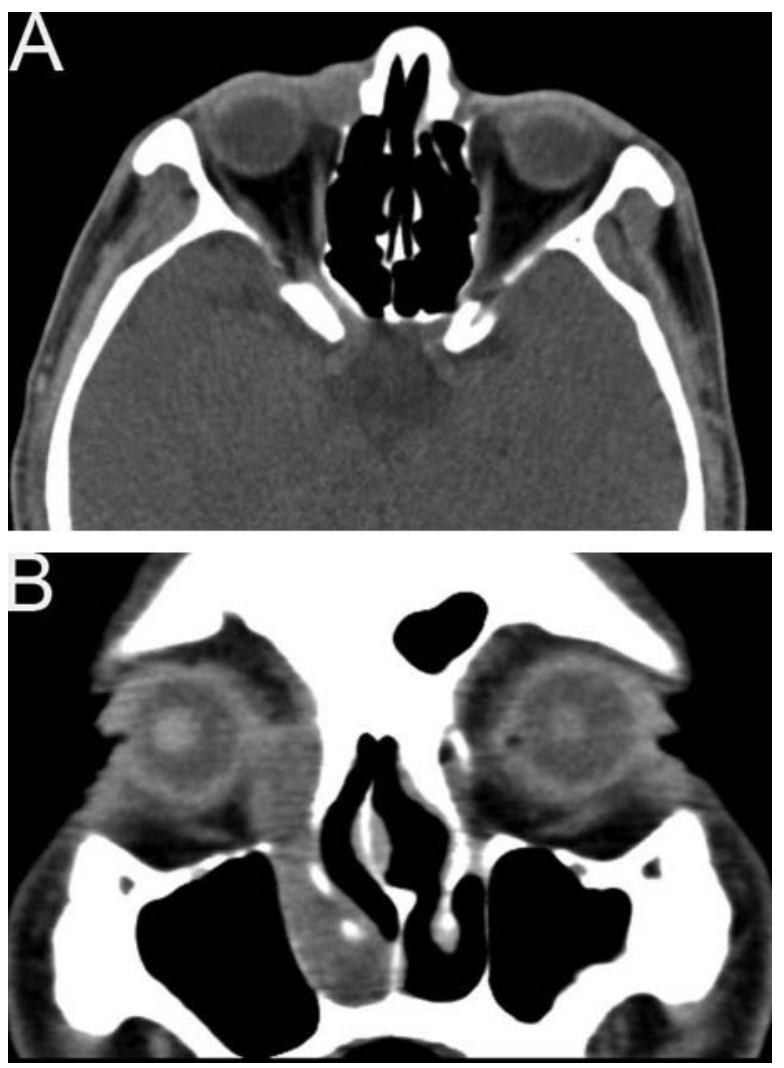

Figure 2 CT findings of melanoma of the right lacrimal sac. (A) Axial CT scans show a soft tissue mass in the right nasolacrimal fossa. There was no evidence of destruction of adjacent bony structures. (B) Coronal CT scans show a soft tissue mass in the right nasolacrimal canal and inferior turbinate.

Biopsy (figure 4) and histological examination of the surgical specimen showed solid growth of malignant cells characterised by the production of melanin pigments and hyperchromatic nuclei with prominent nucleoli (figure $5 \mathrm{~A}$ ). The tumour cells showed strong immunoreactivity to melanoma-specific antibody, HBM-45 (figure 5B) Melan-pan (figure 5C), S-100 (figure 5D) and VIM (figure 5E) in the immunohistochemical examination, whereas the immunoreactivity to the CK protein was negative (figure $5 \mathrm{E}$ ). This histological examination confirmed the diagnosis of malignant melanoma and the resection margins were not free of tumour.

\section{DIFFERENTIAL DIAGNOSIS}

- Chronic dacryocystitis.

\section{TREATMENT}

On formal surgical exploration, a distended, firm lacrimal sac mass was identified and incised. The mass extend into the nasolacrimal duct. The patient underwent wide en-bloc resection of the nasolacrimal duct and surrounding bone and inferior turbinate (figure 6).

The patient underwent 6000 rads of adjuvant irradiation therapy at the right lacrimal region for 4 weeks after surgery. $^{3}$
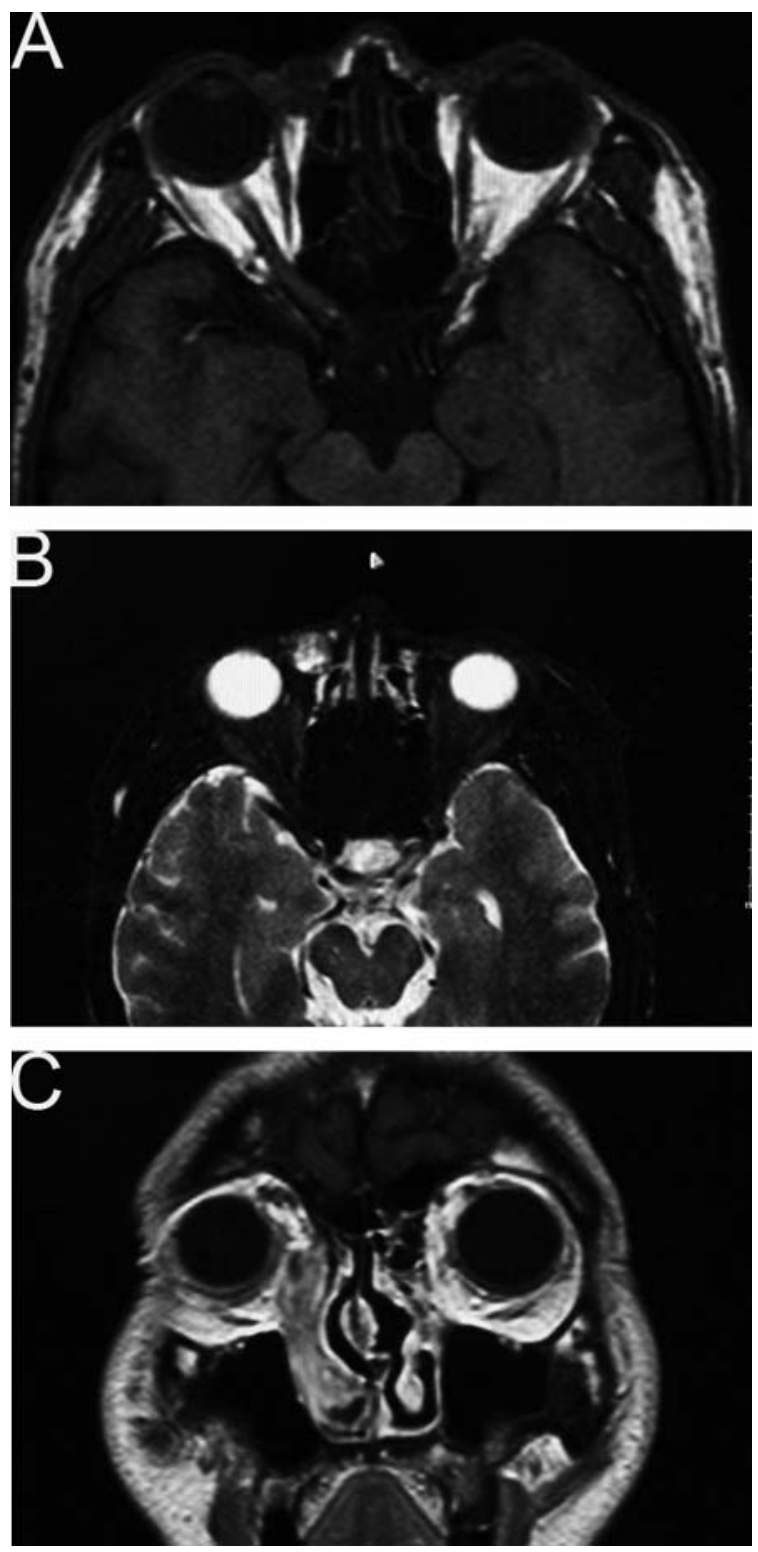

Figure $3 \mathrm{MRI}$ showed proton density image of the right paranasal sinus. Corresponding axial MRI showed T1-weighted lowerintensity (A), T2-weighted highintensity (B) and Coronal MRI gadolinium-enhanced T1-weighted highintensity (C).

\section{OUTCOME AND FOLLOW-UP}

During the 4 months of follow-up after surgery and radiation therapy, the patient had no evidence of local recurrence; however, since then, she has been lost to further follow-up.

\section{DISCUSSION}

Primary neoplasms of the lacrimal sac are rare. Malignant melanoma of the lacrimal sac is extremely rare. Malignant melanoma is a malignancy of the pigment-producing cells known as melanocytes. The skin is usually affected, but other organs are relatively rarely affected such as enteric, respiratory, neurological, oral, conjunctiva, choroid and 


\section{BMJ Case Reports}

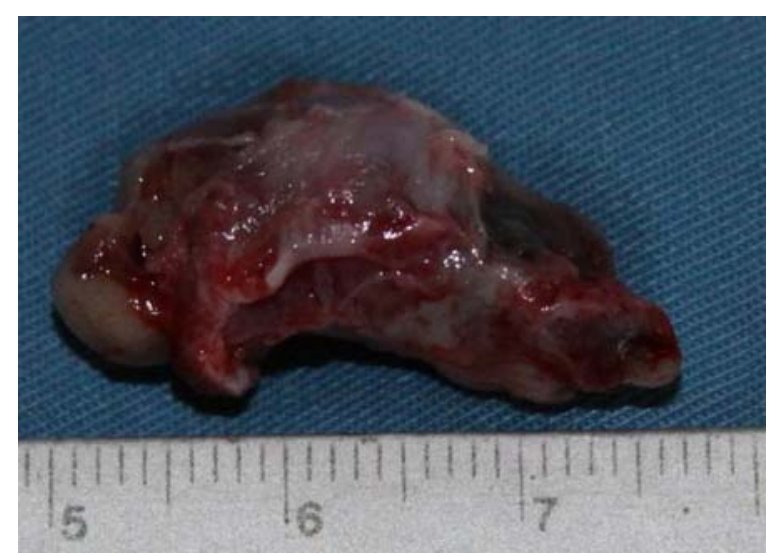

Figure 4 This picture showed the dissected mass.

lacrimal sac. Whereas melanoma accounts for roughly $4 \%$ of all skin cancers, it is responsible for more than $77 \%$ of skin cancer deaths. Mucosal melanoma is a rare entity compared to cutaneous malignant melanoma. Mucosal malignant melanoma of the head and neck represents approximately $8 \%$ of all melanomas that develop in the head and neck, and generally behaves far more aggressively than cutaneous melanoma. ${ }^{4}$

Malignant melanoma was not diagnosed preoperatively in any of the cases. The average age was 59 (range 38-80). There was no significant difference between genders, but the mean age at the time of diagnosis was 64 years for men, and 55 years for women. ${ }^{5}$ They have an insidious onset and may present like chronic dacryocystitis. ${ }^{6} 7$ Presenting features were lacrimal symptoms such as epiphora or blood-stained reflux. Generally, a mass appeared in the medial canthal area and expanded below the palpebral ligament. Therefore, a CT scan and MRI in patients with symptoms of chronic dacryocystitis is an important part of the evaluation. But in most cases, the diagnosis is made at a late stage and usually only after excision or biopsy of the tumour.
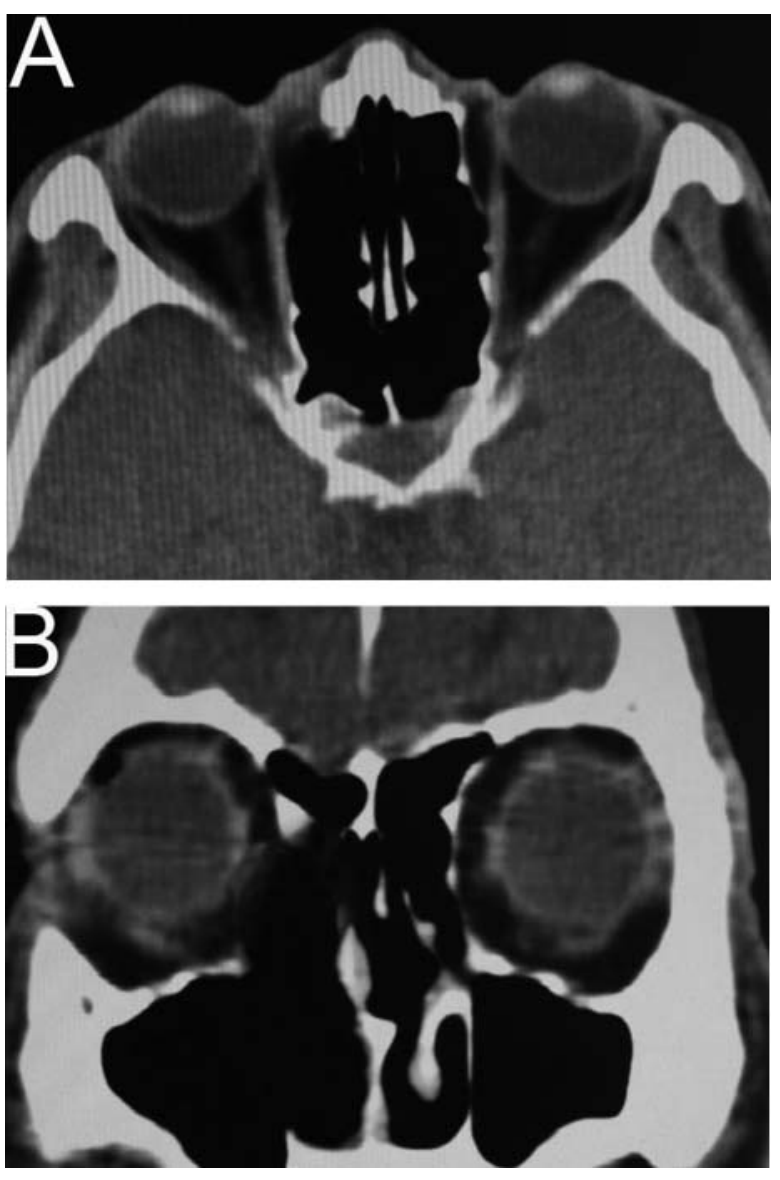

Figure 6 CT findings of melanoma of the right lacrimal sac after surgery. (A) Axial CT scans show that there was no soft tissue mass in the right nasolacrimal fossa. (B) Coronal CT scans show that there was no right nasolacrimal canal and inferior turbinate.

The histogenesis of primary malignant melanoma of the lacrimal sac is not clear; because melanocytes are not normally found in the tissue of the lacrimal duct system.
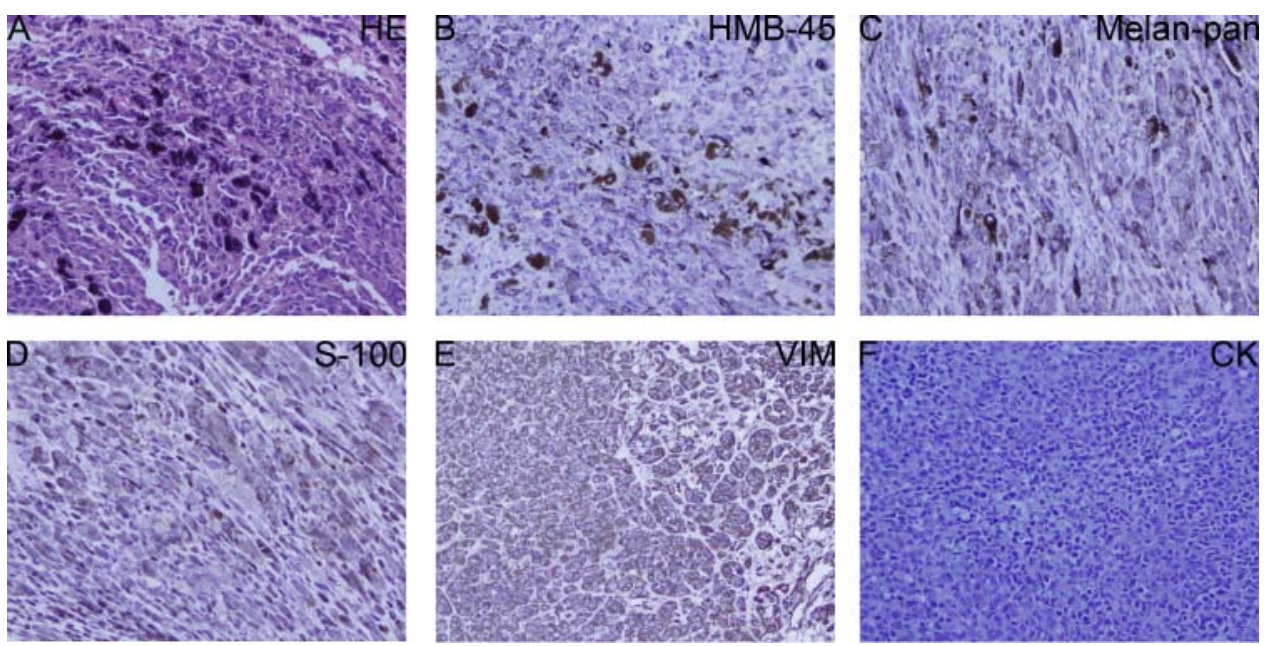

Figure 5 These tumour cells characterised by production of melanin pigments and hyperchromatic nuclei with prominent nucleoli (A). The tumour cells showed strong immunoreactivity to melanoma-specific antibody, HBM-45 (B), Melan-pan (C), S-100 (D) and VIM (E) in the immunohistochemical examination; whereas the immunoreactivity to the CK protein was negative(E). (immunohistochemical staining, $\times 200)$. 


\section{BMJ Case Reports}

It has been postulated that melanocytic cells may either be ectopic beneath the lacrimal sac epithelium during embryological migration of neural crest cells, or they may have migrated into the lacrimal system from the embryological conjunctival sac.

The treatment varies with size and extent of the tumour, and may range from only dacryocystectomy to wide en-bloc resection, postoperative radiotherapy, chemotherapy and immunotherapy in a variety of combinations. ${ }^{6}$ Local recurrence of mucosal malignant melanoma of the head and neck region has been a major factor in treatment failure. Therefore, it has been recently recommended that the resection include a wide field en-bloc excision of the whole lacrimal system and the surrounding tissues followed by irradiation. However, the role of adjuvant therapy such as radiation, chemotherapy and immunotherapy remain controversial. In this case, the patient presented with a palpable mass at the right medial canthal region with bloody discharge. Postoperative radiotherapy was added to the treatment regimen. Considering the natural course and the short follow-up, further evaluation with longer follow-up is needed to determine whether recurrence occurs.

In summary, malignant melanoma of the lacrimal sac is rare and early diagnosis is critical for a favourable prognosis. Therefore, consideration of the possibility of a malignant melanoma of the lacrimal sac is important when considering evaluation and work-up for dacryocystitis. Thus, a CT scan or MRI in the case of persistent dacryocystitis is important. The second most important prognostic factor was the type of surgery consisting of a tumour excision including bony wall and resection. Further study with a larger patient population and longer follow-up is required to determine patient outcome after treatment.
Learning points

- Malignant melanoma of the lacrimal sac is rare and early diagnosis is critical for a favourable prognosis.

- CT-scan in cases of persistent dacryocystitis is important.

Contributors The six authors are justifiably credited with authorship, according to the authorship criteria. In detail: Conception, design, analysis and interpretation of data, drafting of the manuscript, final approval given; acquisition of data, analysis and interpretation of data, final approval given and critical revision of manuscript, final approval given.

\section{Competing interests None.}

Patient consent Obtained.

\section{REFERENCES}

1. HeindI LM, Schick B, Kämpgen $E$, et al. Malignant melanoma of the lacrimal sac. Ophthalmologe 2008;105:1146-9.

2. Sitole S, Zender CA, Ahmad AZ, et al. Lacrimal sac melanoma. Ophthal Plast Reconstr Surg 2007;23:417-19.

3. Nam JH, Kim SM, Choi JH, et al. Primary malignant melanoma of the lacrimal sac: a case report. Korean J Intern Med 2006;21:248-51.

4. Richtig E, Langmann G, Mullner K, et al. Ocular melanoma: epidemiology, clinical presentation and relationship with dysplastic nevi. Ophthalmologica 2004;218:111-14.

5. Gleizal A, Kodjikian L, Lebreton F, et al. Early CT-scan for chronic lacrimal duct symptoms - case report of a malignant melanoma of the lacrimal sac and review of the literature. J Craniomaxillofac Surg 2005:33:201-4.

6. Malik TY, Sanders R, Young JDH, et al. Malignant melanoma of the lacrimal sac. Eye 1997;11:935-7.

7. Fishman G, Ophir D. Malignant melanoma of the lacrimal sac: a case study. Am J Otolaryngol 1999;20:336-9.

This pdf has been created automatically from the final edited text and images.

Copyright 2012 BMJ Publishing Group. All rights reserved. For permission to reuse any of this content visit

http://group.bmj.com/group/rights-licensing/permissions.

BMJ Case Report Fellows may re-use this article for personal use and teaching without any further permission.

Please cite this article as follows (you will need to access the article online to obtain the date of publication).

Li Y-J, Zhu S-J, Yan H, Han J, Wang D, Xu S. Primary malignant melanoma of the lacrimal sac. BMJ Case Reports 2012;10.1136/bcr-2012-006349, Published XXX

Become a Fellow of BMJ Case Reports today and you can:

- Submit as many cases as you like

- Enjoy fast sympathetic peer review and rapid publication of accepted articles

- Access all the published articles

- Re-use any of the published material for personal use and teaching without further permission

For information on Institutional Fellowships contact consortiasales@bmjgroup.com

Visit casereports.bmi.com for more articles like this and to become a Fellow 